\title{
Possibly False Knowledge
}

\author{
Alex Worsnip \\ Forthcoming in the Journal of Philosophy, Issue 112, Volume 5 (2015)
}

Please cite published version

Many epistemologists call themselves 'fallibilists'. Nevertheless, it is widely thought that 'it is possible that $p$ ', taken in a particular way, means something like 'for all I know, $p$ '. And if that is right, it seems like it could not be the case that a subject could know that $p$, and yet that it could be possible, for them, that not- $p$. In other words, a subject could not have knowledge that is, for them, possibly false. Whatever the core insight behind fallibilism is, one might think, it cannot be that subjects can have knowledge that could, for them, be false. ${ }^{1}$

I will argue that, on the contrary, subjects can in fact know things that are, for them, possibly false. My ultimate aim, then, is to vindicate a form of fallibilism that is very robust indeed. Since the main obstacle to accepting such a form of fallibilism consists of various linguistic data about the felicity and infelicity of particular utterances, and that bear on the meaning of 'possibility'-claims, these topics will occupy us for most of this paper. I hope to show not only that, taken as a whole, the data do not support the proposal that subjects cannot have possibly false knowledge, but indeed that they positively favor the proposal that they can.

\section{Preliminaries and clarifications}

The sense of 'possibly' in play is the one widely called 'epistemic possibility', although, for reasons that should be clear from my central claim, I think that this terminology is at least potentially misleading. ${ }^{2}$ If 'epistemic possibility' just means 'what is possible given one's knowledge', as the term 'epistemic' implies, then my claim is trivially false. For suppose a subject knows that $p$. Of course it is not possible that not- $p$ given that $p$. Nevertheless, I am obviously not concerned with a usage of 'possible' that involves something as wide as logical or metaphysical possibility. The usages I am concerned with are roughly those that have been labeled as epistemic, even if my account will make this label somewhat inappropriate. That should not in itself count against my account, since 'epistemically possible' is not a folk term which 'possible' is standing in for in ordinary usage.

I am also not defending the thesis that it is possible that both (i) $S$ knows that $p$ and (ii) it is false that $p$. That is, I am not departing from the assumption that knowledge is factive. Rather, my

For helpful discussion and comments, I am indebted to Julianne Chung, Nathanael Deraney, Keith DeRose, Jessica Keiser, Justin Khoo, Josh Knobe, Jonathan Phillips, Trevor Teitel, Jonathan Vertanen, Bruno Whittle, and a very helpful anonymous referee for this JOURNAL.

${ }^{1}$ For an attempt to argue against fallibilism on these grounds, see Dylan Dodd, "Against Fallibilism," Australasian Journal of Philosophy, LXXXIX, 4 (2011): 665-85. For an attempt to reconstrue fallibilism less ambitiously so that it can accommodate criticisms of this sort, see Jason Stanley, "Fallibilism and Concessive Knowledge Attributions," Analysis, LXV, 2 (2005): 126-31.

${ }^{2}$ Having issued this caveat, I will freely call it 'epistemic possibility' for ease of expression throughout (though see section VII). 
claim is that $S$ can sometimes truly assert 'it is possible that not- $p$ ' even though $S$ knows that $p$. So I am opposing myself to the following popular view:

Knowledge-Possibility Link (KPL). S's utterance of 'it is possible that not- $p$ ' is true only if $S$ does not know that $p .^{3}$

Obviously, KPL is only intended to cover the so-called epistemic usage of 'possible.' So my grounds for rejecting it are not that 'it is possible that not- $p$ ' might express a claim about logical or metaphysical possibility.

There are, as I see it, two main potential reasons to accept KPL. One is that it might seem hard to give an account of the relevant usage of 'possible' that does not bottom out in the speaker's knowledge. One might think there is simply no other clean and satisfying account available; usages of 'possible' that are not logical or metaphysical are just too obscure if not understood in terms of knowledge.

The second reason is a familiar one concerning the badness of what, following Patrick Rysiew, ${ }^{4}$ we can call 'concessive knowledge attributions', that is, claims of the form

(1) I know that $p$, but it is possible that not- $p$.

There is a wide consensus among philosophers that statements of this claim are pretty much always bad, and unlike some of the few existing opponents of KPL, ${ }^{5}$ I will not depart from this consensus. In fact, unlike other existing opponents of KPL, ${ }^{6} \mathrm{I}$ will even allow that the conjunctions expressed by concessive knowledge attributions are always false (not merely that they sound bad for pragmatic reasons).

\footnotetext{
${ }^{3}$ See, for example, Keith DeRose, "Epistemic Possibilities," Philosophical Review, C, 4 (1991): 581-605; John Hawthorne, Knowledge and Lotteries (Oxford: Oxford University Press, 2004), p. 26; Stanley, "Fallibilism and Concessive Knowledge Attributions," op. cit., p. 128; Dodd, "Against Fallibilism," op. cit., p. 667; Andy Egan and Brian Weatherson, "Introduction: Epistemic Modals and Epistemic Modality," in their (eds.) Epistemic Modality (Oxford: Oxford University Press, 2011).

One might alter KPL so that the left-hand side reads 'it is possible for $S$ that not- $p$,' so that 'possible' is used rather than mentioned. I have not done this because it is slightly obscure what it means to say that something is possible for someone, over and above it just being the case that their utterance of 'it is possible that p' would be true. We do not often talk of what is possible for people in ordinary speech, whereas we are well acquainted with sentences of the form 'it is possible that $p$ ' that play the kind of role we are interested in. However, if someone does want to modify KPL in the way just suggested, my central arguments against it would be unaffected.

I have avoided stating KPL as a biconditional since according to some writers, 'it is possible that not- $p$ ' may be false in some situations where $S$ does not know that $p$, namely when knowledge is not yet had but can be gained easily, or when other individuals in some relevant group know that $p$ (see DeRose, "Epistemic Possibilities," ibid.., pp. 591-94; Egan and Weatherson, "Introduction: Epistemic Modals and Epistemic Modality," ibid., p. 3).

${ }^{4}$ See Patrick Rysiew, "The Context-Sensitivity of Knowledge Attributions," Nô̂s, XxxV (2001): 477-514.

${ }^{5}$ Cf., for example, Charity Anderson, "Fallibilism and the Flexibility of Epistemic Modals," Philosophical Studies, CLXVII (2014): 597-606.

${ }^{6}$ Cf., for example, Rysiew, "The Context-Sensitivity of Knowledge Attributions,” ibid.; Trent Dougherty and Patrick Rysiew, "Fallibilism, Epistemic Possibility, and Concessive Knowledge Attributions," Philosophy and Phenomenological Research, LXXVIII, 1 (2009): 123-32.
} 
KPL gives a straightforward explanation of why concessive knowledge attributions express false claims, since given KPL, the two conjuncts in (1) contradict each other. Nevertheless, I will claim that KPL is not the only explanation. I will offer an alternative explanation of why concessive knowledge attributions express false claims in terms of quantifier domain restriction (QDR). This is intended to cast doubt on the second reason for accepting KPL. I also think that the QDR explanation of why concessive knowledge attributions express false claims can be suitably developed and generalized to yield a more general account of epistemic uses of 'possible', thus defusing the first reason for accepting KPL as well. I gesture at this more general account at one point in section II below. But my focus here will be on the explanation of concessive knowledge attributions and related cases, rather than developing a fully general theory of epistemic modals.

Do not think, however, that I am solely seeking to neutralize the argument from concessive knowledge attributions to KPL. Rather, I am going to argue that the QDR explanation of concessive knowledge attributions is preferable to the KPL explanation, since it generalizes better to similar, related cases that provide positive data against KPL. So, I am not merely going to argue that the QDR account is a viable rival to the KPL account; I am going to argue that it is preferable. In the course of doing so, I hope to provide a positive case for the claim that subjects can have possibly false knowledge.

I proceed as follows. Section II explains the two competing views. Sections III and IV argue, from two different sorts of cases, that QDR is superior to KPL. Section III examines a very important and prevalent kind of case that, to my knowledge, has been overlooked in the literature: conjunctions of possibility-claims with claims of the form 'I think I know...'. Section IV examines the more familiar case of conjunctions of possibility-claims with unqualified assertions that do not make any mention of knowledge. Section $\mathrm{V}$ explains how the view developed here makes good on the claim that subjects can have possibly false knowledge, and section VI deals with an important question about the QDR view about the ordering of conjuncts. Section VII tentatively takes up some broader questions that arise from the rejection of KPL, about whether so-called epistemic possibility is really a single category.

\section{Explaining the two competing views}

Modal sentences like 'it is possible that $p$ ' quantify over possible worlds. 'It is possible that $p$ ' is true just if there is a possible world in the relevant domain of possible worlds in which $p$. The relevant domain of possible worlds can be thought of as being determined by a modal base. As I will use the term, the modal base is a set of propositions. ${ }^{7}$ If a proposition is in the modal base, then modals will quantify only over worlds in which that proposition is true. So the domain of possible worlds over which modals quantify is restricted to the set of possible worlds that are compatible with all the

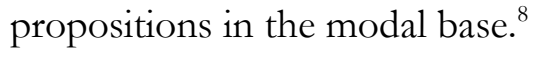

\footnotetext{
${ }^{7}$ Some literature may use 'modal base' to refer to the set of worlds compatible with these propositions. This is not how I will talk here, and reading my claims this way will lead to misunderstanding them. But everything could be translated into this language if it had to be.

${ }^{8}$ This framework for understanding modals is due to Angelika Kratzer (see Kratzer, "The Notional Category of Modality," in H.-J. Eikmeyer and H. Rieser, eds., Words, Worlds, and Contexts: New Approaches in Word Semantics (Berlin: de
} 
This much the KPL advocate can agree with. Now we can understand the KPL view as claiming that, for all possible conversational contexts, the modal base always includes the speaker's knowledge - that is, the propositions that the speaker knows - at the time of utterance. Of course, this does not mean that the propositions in the modal base never change: speakers can gain or lose knowledge as they gain or lose beliefs and evidence.

It might seem that the KPL view also allows the modal base to shift without changes in belief and evidence if contextualism about knowledge is true: that is, if 'knows' is semantically context-sensitive. After all, doesn't contextualism say that subjects lose knowledge in "highstandards" contexts, and gain it in "low-standards" contexts? While this is a tempting way to speak, it is misleading.' Contextualism says that the word 'knows' has a different semantic value when uttered in different contexts. Suppose it is the case, as contextualism says it can be, that ' $S$ knows that $p$ ' is true when uttered in a low-standards context and false when uttered in a high-standards context. Contextualism says that this is because 'knows' has a different semantic value in the two contexts; correspondingly, the proposition expressed is different. Simplifying somewhat, we can say that in the low-standards context, ' $S$ knows that $p$ ' expresses the proposition that $S$ knows LO $_{\text {th }} p$, and in the high-standards context, ' $S$ knows that $p$ ' expresses the proposition that $S$ knows $\mathrm{HI}_{\mathrm{HI}}$ that $p$. However, by the contextualist's lights, it is still the case that $S$ knows $_{\mathrm{LO}}$ that $p$ in the high-standards context, and that $S$ does not know that $p$ in the low-standards context. It is just that, in each case, the context makes it the case that this proposition cannot be expressed using the bare word 'knows'.

So, there is no individual semantic value for 'knowledge' on which it can be said that the subject "loses" knowledge in high-standards contexts. And KPL uses the word 'knows' rather than mentioning it, by referring to whether $S$ knows that $p$, rather than whether ' $S$ knows that $p$ ' would be true in S's (or any other) particular context of utterance. So, on the KPL view as it stands, changes in the standards for 'knows' at S's context of utterance would not make a difference to whether some proposition makes it into the modal base that determines the semantic value of S's possibility-claim.

Indeed, as it stands KPL sits uneasily with contextualism. According to the contextualist, there are many potential semantic values of 'know'. But which of these semantic values is the one that features in KPL when it uses 'know'? It seems odd, and arbitrary, to pick one particular value of 'know', out of all the potential semantic values it can take in different contexts of utterance, that is supposed to provide the constraint on possibility-claims for all contexts of utterance. On the other hand, if the contextualist says that KPL is true on every possible standard for 'know', this amounts to saying that 'it is possible that not- $p$ ' is true only if ' $S$ does not know that $p$ ' is true at every possible standard for 'know'. That is, 'it is possible that not- $p$ ' comes out false whenever the subject knows that $p$ by any conceivable standard - including the maximally permissive standard - even if 'it is possible that not- $p$ ' is itself uttered in a context where such a standard for 'knows' is not the one in play. This is surely too strong a constraint on possibility-claims: it will count far too few such claims as true. ${ }^{10}$

Gruyter, 1981), pp. 38-74). Kratzer's framework includes two parameters for the semantics of modals-a modal base and an ordering source. Here we can generally ignore the ordering source parameter.

${ }^{9}$ See Keith DeRose, The Case for Contextualism (Oxford: Oxford University Press, 2009), chapter 6, especially pp. $212-25$.

${ }^{10} \mathrm{It}$ is worth noting that the same issue does not arise in combining "interest-relative invariantist" accounts (of the kind defended by, amongst others, Hawthorne, Knowledge and Lotteries, op. cit., and Jason Stanley, Knowledge and Practical Interests 
If, as is much more plausible, the contextualist wants to say instead that the standards for 'possible' shift with those for 'knows', then she has to modify KPL. Rather than using 'knows', the right-hand side of the principle can mention 'knows', just as the left-hand side mentions 'possible': ${ }^{11}$

Contextualist Knowledge-Possibility Link (CKPL). S's utterance of 'it is possible that not$p$ ' is true only if $S$ 's assertion of 'I do not know that $p$ ' at the same context would be true. $^{12}$

I will return to the contextualist variant of KPL in section V. For now, I will focus on explaining the QDR view.

The QDR view posits that the modal base can shift with context in a different way. In particular, when a speaker asserts that $p$, this can be seen as a proposal to update the modal base with the proposition that $p \cdot{ }^{13}$ So, when you assert that $p$, if all goes right, ${ }^{14}$ you restrict the domain over which you subsequently quantify to the $p$-worlds.

There are different ways in which one might spell this out. One reasonable proposal would be to say that an assertion updates the modal base via updating the common ground of the conversation. As I have said, however, my primary concern is not to develop a comprehensive account, but to argue that subjects can have possibly false knowledge. So I do not need to commit on the exact details of the best form of the QDR account. All I need is the claim that assertions are capable of updating the modal base. But I do think the common ground model is a reasonable working model for the QDR theorist, and it may sometimes help the reader to think of things this way.

Here is how the QDR view handles the badness of ' $\mathrm{I}$ know that $p$, but it is possible that not$p^{\prime}$. When you assert that you know that $p$, if all goes right, you restrict the domain of possible worlds over which subsequent utterances quantify to the possible worlds in which you know that $p$. But, quantifying only over the worlds in which you know that $p$, there are no worlds in which not- $p$ (since knowledge is factive). So, given the restriction on the domain achieved by the first conjunct, the

(Oxford: Oxford University Press, 2005)) with KPL. Since an interest-relative invariantist posits a stable semantic value for 'knows', with the facts about whether a subject knows a proposition shifting depending on practical circumstances, she can simply accept KPL as it stands, and say that the truth-value of talk about possibility also shifts with practical circumstances.

${ }^{11}$ For discussion of a related, parallel point about the need for contextualists to "relativize" the knowledge account of assertion, see Hawthorne, Knowledge and Lotteries, op. cit., pp. 85-91, and DeRose, The Case for Contextualism, op. cit., pp. 257-62.

12 See Keith DeRose, “Simple 'Might's, Indicative Possibilities and the Open Future," The Philosophical Quarterly, XLVIII, 100 (1998): 67-82, at p. 70. DeRose (p.c.) says that he now accepts CKPL, not KPL.

${ }^{13}$ Such a picture is familiar from the work of Robert Stalnaker. See Stalnaker, Context and Content: Essays on Intentionality in Speech and Thought (Oxford: Oxford University Press, 1999), especially chapters 1-5; "Common Ground," Linguistics and Philosophy, XXV (2002): 701-21. It also concords to some degree with the "update semantics" developed by Frank Veltman, "Defaults in Update Semantics," Journal of Philosophical Logic, XV (1996): 221-61, and applied by Anthony Gillies, “A New Solution to Moore's Paradox," Philosophical Studies, CV (2001): 237-50, especially p. 247.

${ }^{14}$ If your assertion that $p$ is false, the proposition that $p$ plausibly does not actually get added to the modal base. 
second conjunct ('it is possible that not- $p$ ') expresses a false proposition in the new context. So the conjunction as a whole is false. ${ }^{15}$

So we have a rival explanation of the badness of utterances of the form ' $\mathrm{I}$ know that $p$, but it is possible that not- $p$ '. Unlike the KPL view, the QDR view makes what is actually asserted in a conversation crucially relevant to the modal base. It explains the badness of concessive knowledge attributions not by the fact that the subject knows that $p$, but by the subject's asserting that she knows that $p$. Nevertheless, it takes this assertion to have real consequences for the truth-value of subsequent modal utterances, and not just to make those utterances pragmatically inappropriate.

The existence of the QDR explanation in itself neutralizes the contention that the KPL account is the only account that can explain the badness of concessive knowledge attributions. Now, however, I will offer some positive arguments for my view over the KPL view by appealing to two other kinds of case. In each case KPL has problems, but QDR gets the right verdict.

\section{3. 'I think I know...'}

In the first kind of case, $S$ makes an utterance of roughly one of the following forms:

(2) I think I know that $p$, but it is possible that not- $p$.

(3) I think I know that $p$, but it is possible that $q$,

where $q$ is an obviously incompatible counter-possibility.

Here are some concrete examples:

A: Do you know what the capital of South Africa is?

B: Yes, I think I know the answer to your question-Pretoria. But it might be Johannesburg.

I think I know that it is 6pm. But of course my clock could be broken, and so it is possible that it is not $6 \mathrm{pm}$.

[Scientist, upon making a new breakthrough]: I believe that I now know what causes electromagnetic radiation. But it is always possible that some future scientist will show that I was wrong.

I think I know what caused my recent stomach pains-stress. But it is possible that they were caused by something else.

\footnotetext{
15 What if your assertion that you know that $p$ is false, and so the proposition that you know that $p$ is not added to the modal base? (See the previous footnote.) In such a case, the utterance is still defective because from the speaker's point of view, the modal base has been updated, even though in fact it has not been: it is enough for there to be a "clash" that were the first conjunct to have been true, its utterance would have made the latter conjunct false. Moreover, cases where the first conjunct ('I know that $p$ ') is false are obviously also cases where the conjunction as a whole is false. So the account predicts that, whether the first conjunct is true or false, the conjunction as a whole - one way or another - comes out false (as not merely pragmatically inappropriate).
} 
These sound felicitous. Just so that you do not suspect that the goodness of (4)-(7) is due to something other than the 'I think I know' qualification, compare them with their unqualified counterparts, which are concessive knowledge attributions in the original sense:

(8) A: Do you know what the capital of South Africa is?

B: \#Yes, I know the answer to your question-Pretoria. But it might be Johannesburg.

(9) \#I know that it is 6pm. But of course my clock could be broken, and so it is possible that it is not $6 \mathrm{pm}$.

[Scientist, upon making a new breakthrough]: \#I now know what causes electromagnetic radiation. But it is always possible that some future scientist will show that I was wrong.

\#I know what caused my recent stomach pains—-stress. But it is possible that they were caused by something else.

These are bad. So it seems that what makes (4)-(7) good is the 'I think I know' qualification.

The KPL view, however, makes the wrong prediction here. (So does CKPL; see section V below.) According to the KPL view, if it is epistemically possible for $S$ that not- $p$, then $S$ does not know that $p$. However, if that is right, then when you assert a statement of the form of (2), you report the belief that you know that $p$, and then say something - that it is epistemic possible that not- $p$ - that amounts to saying that this belief is false. Now, it is true (arguably ${ }^{16}$ ) that there is no contradiction between the proposition that you believe that $p$ and the proposition that not- $p$. Nevertheless, as Moore's Paradox famously shows, utterances of the form

I believe that $p$, but not- $p$

sound very bad. An instance of this is provided by claims of the form:

$$
\text { I believe that I know that } p \text {, but I do not know that } p \text {. }
$$

The KPL view says that (4)-(7) should have the feel of (13). If the possibility that not- $p$ entails that you do not know that $p$, then you should not be free to conjoin the possibility that not- $p$ with even the belief that you know that $p$ without something defective happening. But this does seem okay, so the KPL view makes the wrong prediction.

By contrast, the QDR view predicts the intuitive data nicely. When you say 'I believe that I know that $p$, but it is possible that not- $p$,' the first clause restricts the domain over which the modal in the second clause quantifies only to worlds in which you believe that you know that $p$. But since there are plenty of worlds where you believe that $p$, yet it is not the case that $p$, the second clause can still express something true. By contrast, when you assert that you know that $p$, you restrict the domain

\footnotetext{
${ }^{16}$ For a view that makes utterances of these claims contradictory, albeit in a dynamic setting, see Gillies, "A New Solution to Moore's Paradox," op. cit.
} 
to worlds in which you know that $p$. And there are no worlds where you know that $p$ and yet it is not the case that $p$. So this explains why (4)-(7) seem okay where (8)-(11) do not. ${ }^{17}$

At this point, a defender of KPL might object that the foregoing comparison rests upon a mistaken account of the semantic effect of 'I think' and 'I believe'. ${ }^{18}$ According to many linguists, these phrases are "hedges," which function like evidentials in other languages. ${ }^{19}$ On this view, saying 'I believe that $p$ ' is (at least often) not merely (or even primarily) a belief-report- that is, an assertion of the proposition that you believe that $p \cdot{ }^{20}$ Rather, it is also a way of performing a speech act with respect to the bare proposition that $p$, but weaker than outright assertion. The effect of the weakened force of the speech act is to propose to add some kind of modally weaker proposition to the modal base. Rather than proposing to add the proposition that $p$, as an outright assertion would, it proposes to add the proposition that it is possible that $p$, or that it is likely that $p$, or similar.

I do not deny this "hedging" account. Nor am I claiming that the hedging account on its own has any problem with utterances of the form of (4)-(7). But what I do deny is that the hedging account gets KPL off the hook with its problems explaining (4)-(7). Suppose that the hedging account is right. In order to be maximally charitable to KPL, let us suppose that the effect of 'I think that $p$ ' is just to (propose to) add to the modal base the proposition that $p$ is possible. ${ }^{21}$ Then, what saying 'I think I know that $p$ ' commits you to is that it is possible that you know that $p$. In sentences (4)-(7), you combine this with a claim that it is possible that not- $p$. But according to KPL, if your utterance of 'it is possible that not- $p$ ' is true, then it is guaranteed that you do not know that $p$. So, if you are committing yourself to the claim that it is possible that not- $p$, you are also committing yourself to the claim that you do not know that $p$. So it is incoherent for you to also claim that it is (epistemically) possible that you do know that $p$, as you do by saying 'I think I know that $p$ ' according to the hedging account. (This is just an instance of the general incoherence of simultaneously claiming that $p$ and that it is possible that not- $p$, a phenomenon we turn to in the next section.) So, (4)-(7) should still be incoherent on the KPL view, even if we adopt the hedging view of "I think".

By contrast, the hedging view actually sits very nicely with the QDR view. Indeed, it just gives the QDR view a new way of explaining why (4)-(7) are good, but (8)-(11) are bad. It is because, whereas ' $\mathrm{I}$ know that $p$ ' adds the proposition that one knows that $p$ to the modal base, 'I think I know that $p$ ' only adds the proposition that it is likely that $p$ (or similar) to the modal base. The former update will make 'it is possible that not- $p$ ' come out false, given the restricted set of

\footnotetext{
${ }^{17}$ Likewise, there is nothing wrong with saying, 'I believe that $p$, but it is possible that not- $\phi$,' in contrast to the badness of " $p$, but it is possible that not-p."

${ }_{18}$ Many thanks to an anonymous referee for sharpening this objection.

${ }^{19}$ See, for example, Sarah E. Murray, "Varieties of Update," Semantics and Pragmatics, VII, 2 (2014): 17-20.

${ }^{20}$ Murray does not deny that it also has this function, even in cases where it also functions as a hedge. Indeed, she positively says that the utterance has both functions (ibid., p. 18).

${ }^{21}$ In fact, I do think that this is being too charitable. When one says, "I think the Dodgers will win the World Series," one commits oneself to more than the possibility (or even the "serious" possibility) that the Dodgers will win. Otherwise, it could be okay to say, "I think the Dodgers will win the World Series, and I think the Orioles will win the World Series," since both such outcomes could be serious possibilities. And it would also be okay to say, "I think the Dodgers will win the World Series, but it's more likely that they won't." But these utterances are not okay. This suggests that the effect of 'I think that $p$ ' commits one to something stronger than $p$ 's (serious) possibility-perhaps, at minimum, $p$ 's being more likely to be true than false. Murray does not deny this — she affirms that different hedges come with different "levels of commitment" (Murray, "Varieties of Update," ibid., p. 18).
} 
worlds that 'possible' will now quantify over. The latter update will not necessarily have this effect. This is the most natural explanation of the goodness of (4)-(7) on the hedging view, and it unifies the hedging view with the QDR view.

\section{4. 'P, but it's possible that not-P'}

Next consider utterances of the form

$$
p \text {, but it is possible that not- } p^{22}
$$

Here there is no mention of knowledge. Let us use the same adapted examples again:

A: What is the capital of South Africa?

B: \#It's Pretoria. But it might be Johannesburg.

\#It's 6pm, but of course my clock could be broken, and so it is possible that it is not $6 \mathrm{pm}$.

[Scientist, upon making a new breakthrough]: \#Electromagnetic radiation is caused by atoms absorbing energy. But it is always possible that some future scientist will show that this is wrong.

\#My recent stomach pains were caused by stress, but it is possible that they were caused by something else.

These sound just as bad as (8)-(11). And QDR predicts why, in a way that is pleasingly parallel to the explanation of the badness of (8)-(11). When you assert that $p$, you narrow the domain of possible worlds over which your subsequent modal quantifies to $p$-worlds. So the assertion 'it is possible that not- $p$ ' comes out false, just as it came out false when you had asserted 'I know that $p$ '. The QDR view says that there is nothing particularly special about the fact that (8)-(11) involve knowledge-claims. It is just that since knowledge is factive, all the worlds in which you know that $p$ are $p$-worlds.

KPL cannot itself explain what is bad about (14). Since the KPL principle is about the incompatibility of knowledge with epistemic possibility to the contrary, it is silent about cases that do not involve knowledge.

Now on its own this is not a fatal objection to KPL. For the KPL advocate can appeal to the knowledge account of assertion: the assertion that $p$ is appropriate only if you know that $p$ (KAA). ${ }^{23}$ Put this together with KPL, and we get the result that the assertion that $p$ is appropriate only if there is no epistemic possibility for you that not- $p$.

\footnotetext{
22 Seth Yalcin (“Epistemic Modals,” Mind, CXVI, 464 (2007): 983-1026) calls such assertions 'epistemic contradictions' and shows that they are not just instances of Moore's paradox.

${ }^{23}$ See DeRose, "Epistemic Possibilities," op. cit., pp. 597-98; Dodd, “Against Fallibilism,” op. cit. For an influential defense of KAA, see Timothy Williamson, Knowledge and Its Limits (Oxford: Oxford University Press), chapter 11.
} 
While this explanation does, perhaps, work, ${ }^{24}$ it draws attention to a weakness in the positive case for KPL. Advocates of KPL tend to take it that KPL is just the obvious explanation of the badness of concessive knowledge attributions, that is, claims like (8)-(11). The two conjuncts sound bad together, so the obvious, simplest explanation is that the truth of a knowledge-claim and the truth of an epistemic possibility claim to the contrary are incompatible. But no one would be drawn to an analogous explanation of the badness of (15)-(18), that is, claims of the form of (14). Such an explanation would go like this: ' $p$, but it is possible that not- $p$ ' sounds bad, so the obvious, simplest explanation is that the truth of an utterance ' $p$ ' is incompatible with the truth of an utterance of 'it is possible that not- $p$ '. That is:

Truth-Possibility Link (TPL). S's utterance of 'it is possible that $p$ ' is true only if $p$.

But TPL is a crazy doctrine. It means that we speak falsely whenever we speak of epistemic possibilities that, as it turns out, do not actually obtain. ${ }^{25}$ So it is obvious that an argument from the badness of (15)-(18) to TPL is not a strong one. But then why should we take there to be a good argument from the badness of concessive knowledge attributions (e.g. (8)-(11)) to KPL? The analogy to TPL calls into serious doubt that the badness of concessive knowledge attributions is really strong evidence for KPL. Thus, the defender of KPL faces a burden to explain the asymmetric conclusion that the badness of concessive knowledge attributions like (8)-(11) gives us conclusive reason to believe KPL, but the badness of (15)-(18) does not give us conclusive reason to believe TPL.

The presumed answer to this could just be that whereas there are alternative explanations of the badness of (15)-(18) besides TPL, there are no alternative explanations of the badness of (8)(11) besides KPL. ${ }^{26}$ But the very existence of the QDR account shows that this is false. Moreover, the QDR account can give a completely parallel explanation of the badness of concessive knowledge attributions (such as (8)-(11)) and that of (15)-(18). It does not apply an explanation in one case that would be obviously mistaken in the other; rather, it explains the badness in exactly same way. It is thus more elegant than KPL, and consequently it does not face the explanatory burden that KPL does of explaining an asymmetric conclusion.

This advantage of elegance is especially important because the KPL view has to posit another striking asymmetry. The KPL view purports to explain why utterances of sentences like (8)(11) are actually guaranteed to be false, as a result of their semantic content. By contrast, however, even with the help of KAA, KPL can only attribute pragmatic inappropriateness to utterances of sentences (15)-(18). On this view, such utterances would involve violations of the knowledge norm of assertion, but they might still be true. This is a striking asymmetry, when the problem behind

\footnotetext{
24 Though Yalcin ("Epistemic Modals," op. cit., pp. 991-93) throws doubt on this. As Yalcin points out, regardless of the inappropriateness of asserting that $p$ when you do not know that $p$, one can suppose $p$ without knowing that $p$. Yet there is still something wrong with saying "suppose that $p$, but it is possible that not- $p$." This suggests that the kind of inappropriateness generated by violating KAA may not fully explain the badness of (15)-(18).

${ }^{25}$ To adapt a point made by Jeremy Fantl and Matthew McGrath ${ }_{2}$ Knowledge in an Uncertain World (Oxford: Oxford University Press, 2009), at p. 17: if TPL were true then one should be able to infer from it and 'it is possible that $p$ ' that p. See also Yalcin, "Epistemic Modals," op. cit., p. 982.

${ }^{26}$ Cf. DeRose, "Epistemic Possibilities," op. cit., p. 597; Dodd, “Against Fallibilism,” op. cit.
} 
both sets of utterances feels so similar. By contrast, the QDR view yields the result that utterances both of (8)-(11) and of (15)-(18) are guaranteed to be false.

A similar point holds with respect to third-person versions of sentences like (8)-(11), of the form 'Susan knows that $p$, but it is possible (for me) that not- $p$ '. ${ }^{27}$ Again, to explain the badness of these sorts of utterances, the advocate of KPL has to turn to KAA for help, since there is no contradiction, by KPL's lights, between Susan's knowing that $p$ and its being possible for the speaker that not- $p .{ }^{28}$ And again, this combination of KPL and KAA gives us only an explanation of the pragmatic inappropriateness of third-person concessive knowledge attributions; they could still be true by the lights of this account. Yet it seems strange that the explanation would be pragmatic in thirdperson cases, but semantic in first-person cases. Once again, the QDR view posits no such asymmetry. Once we have added the proposition that Susan knows that $p$ to the modal base, the factivity of knowledge guarantees that subsequent utterances of 'it is possible that not- $p$ ' come out false. The explanation is exactly the same as it was in the first-person case.

Summing up the last two sections: the KPL explanation of the badness of concessive knowledge attributions both overgeneralizes and undergeneralizes. It overgeneralizes to hedged "I think I know" analogues of concessive knowledge attributions (like (4)-(7)), by predicting that they will sound bad when they sound fine. And it undergeneralizes in not generating an explanation of the badness of claims like (15)-(18), without recourse to additional machinery that it doesn't invoke in the case of concessive knowledge attributions. By contrast, my QDR account yields the right predictions (without additional machinery) in both of these extensions.

\section{Why this is possibly false knowledge}

Even accepting all of this, one might wonder whether QDR really vindicates the thought that we can have possibly false knowledge, as I promised it would. QDR is a view about language. One might think: if you can never assert both that it is possible that not- $p$ and that you know that $p$ together, is knowledge really in any good sense compatible with the epistemic possibility of error?

Here the contextualist form of KPL (CKPL) comes back. It might be suggested that CKPL and QDR are, in fact, compatible. Perhaps the way that 'I know that p' utterances restrict the domain of quantification so as to preclude one from adding 'it's possible that not-p' - as the QDR account posits - is one of a larger set of mechanisms by which the contextually variable standards for 'knows' and 'possible' are coordinated, as CKPL says that they are, in such a way as to preclude its ever being the case both that you count as 'knowing' that $p$ and that it's possible' for you that not$p$, given the standards of any single context. If the standards for 'knows' and 'possible' are coordinated in this way, then to describe us as having "possibly false knowledge" must rest on a kind of tacit equivocation, invoking standards for 'possibly' and 'knowledge' that cannot belong to the same context of utterance.

It is true that, as they stand, CKPL and QDR are compatible, and so could in principle be combined in this way. The problem with this proposal, however, is that CKPL, just as much as the

\footnotetext{
${ }^{27}$ Many thanks to an anonymous referee for drawing my attention to this.

28 See Stanley, "Fallibilism and CKAs."
} 
original KPL, commits us to the wrong predictions about claims like (4)-(7). ${ }^{29}$ In these examples, someone makes an utterance of the form 'I think I know that $p$, but it is possible that not- $p$ '. CKPL says that, given the particular context of utterance and the resulting semantic values for 'knows' and 'possible', it cannot be the case that both 'I know that $p$ ' and 'it is possible that not- $p$ ' express truths. But again, this should make (4)-(7) bad. At the standards at which 'it is possible that not- $p$ ' is true, it should also be the case that 'I know that $p$ ' is false. But if that is right, then the utterance of 'I think I know that $p^{\prime}$ should be infelicitous, for the same reasons given in section III for the simpler KPL account. So we should reject CKPL, even as part of a package that also includes QDR.

By contrast, if ' $\mathrm{I}$ think I know that $p$, but it is possible that not- $p$ ' is felicitous, this positively affirms that there can be an epistemic possibility for you that not- $p$ without this ruling out the claim that you know that $p$ - even at standards for 'knowing' that $p$ that are compatible with mentioning the possibility that not- $\not$. Take the scientist from (6). She acknowledges that electromagnetic radiation might not be caused by what she thinks causes it. With that, she acknowledges that she might not know what causes electromagnetic radiation. That much is guaranteed by factivity: if it is possible for her that not- $p$, then it is also possible for her that she does not know that $p$, a fortiori. However, if her utterance is felicitous, then it is also still a possibility-indeed, a strong possibilitythat she does know that $p$ (again, even at standards consistent with a context of utterance where she can truly say 'it's possible that not-p'). And if that possibility does obtain-in this case, if she does know what causes electromagnetic radiation-then she knows this compatibly with the epistemic possibility that something else causes electromagnetic radiation. She has possibly false knowledge. So although QDR itself does not entail that we can have possibly false knowledge, the examples that tell in favor of it and against KPL (both in its original and contextualist variants) do show that we can have possibly false knowledge. And QDR (unlike KPL and CKPL) is compatible with this.

Nevertheless, one might insist, the QDR account still suggests that, when it is epistemically possible for a subject that not- $p$, this subject at least cannot appropriately claim this knowledge, at least not without hedging with an 'I think'. But I do not think that we need to say even this. Were the subject simply to assert 'I know that $p$ ', we may claim, she would speak truly and appropriately. Likewise, were she to simply assert 'it is possible that not- $p$ ', she would speak truly and appropriately. It is just that she cannot freely conjoin the two, because the claim to knowledge is a proposal to update the modal base in a way that will make the claim of possibility false. We might call this a 'dynamic contradiction'. ${ }^{30}$ Two assertions are dynamically contradictory just if either can be asserted truly in a given context, but they cannot be asserted together because of the way that one or more of them would update that context, thus making the other false.

Dynamic contradictions are certainly interesting, but I do not think that they are especially strange, as they can arise with other context-sensitive terms too. Consider gradable adjectives such as 'flat'. You and I are sitting at a table. In the context, it would be perfectly appropriate and true for me to say, "This table is flat." It would likewise be true and appropriate for me to say, "This table

\footnotetext{
${ }^{29}$ This is not to say that contextualism about 'knows' is false. A contextualist about 'knows' need not be committed to CKPL.

${ }^{30}$ Kai Von Fintel and Antony Gillies ("An Opinionated Guide to Epistemic Modality," Oxford Studies in Epistemology, II (2007): 32-62, at p. 57) call it 'inconsistency' within their dynamic framework.
} 
has little kinks and flecks in its surface." But I cannot conjoin the two, because the latter updates the context in a way that makes the former false, by raising the standards for flatness.

Does the fact that 'I know that $p$ ' and 'it is possible that not- $p$ ' are dynamically contradictory mean that the infallibilist spirit behind KPL ultimately still wins the day? I do not think so. For again, remember that ' $p$ ' and 'it is possible that not- $p$ ' are likewise dynamically contradictory. But no one would take that to vindicate the spirit behind TPL, the absurd claim that an utterance of 'it is possible that $p$ ' is true only if $p$. Moreover, as explained above, the felicity of 'I think I know that $p$, but it is possible that not- $p$ ' is evidence that ordinary usage recognizes a positive compatibility between knowledge and the possibility of error. So the dynamic contradiction between 'I know that $p$ ' and 'it is possible that not- $p$ ' does not mean that ultimately, infallibilism wins the day.

\section{The ordering of the conjuncts}

This seems an appropriate point to address a natural question about the QDR view. In the examples of concessive knowledge attributions that I gave, the claim to know that $p$ comes first, and the claim about the possibility that not- $p$ comes second. The QDR view explains the badness of the conjunction by saying that the first conjunct updates the context so that the latter is false. But what if the order is reversed, so that the speaker says, "It is possible that not- $p$, but I know that $p$ "? Isn't that just as bad?

In general, I agree that reversing the order of the conjuncts does not improve the felicity of the utterance. There are some exceptions to this. One such example is due to Anthony Gillies. ${ }^{31}$ The doorbell rings. You say “That'll be the pizza delivery man!" I reply, just as I get to the door, "Well, it might not be - it could be my annoying neighbor." I open the door and say, "It is the pizza delivery man!" Here this ordering is okay, whereas the reverse would not be. Clearly, however, what explains the felicity is an evidential update between my two assertions that occurs when I open the door: I see the pizza delivery man. There may be cases where the evidential update is somewhat less pronounced, and amounts to something more like a process of reflection. For example, you might say, "Could that be that pizza delivery man?," and I might say, "It could be," and then reflect a bit and say, "But I only ordered the pizza two minutes ago. It's not going to be him." Still, however, there is some kind of update going on. In the new context following my reflection I could just as well say, "It can't be him." Absent such an update, the reversal of the order of the conjuncts does not seem to make the utterance more felicitous.

Is this a fatal problem for the QDR account? I do not think that it is. What the QDR theorist should say is simply that the "reversed" conjunction as a whole is false, because the second conjunct updates the relevant context for the utterance as a whole. The first conjunct is false because the worlds that 'possible' (as it appears in the first conjunct) quantifies over can be restricted by the second conjunct. In other words, the QDR theorist should deny that the syntactic ordering of the conjuncts is what matters on her view (barring relevant evidential updates or context "resets"

${ }^{31}$ Gillies, “A New Solution to Moore’s Paradox,” op. cit., p. 240. 
between the utterances of the two conjuncts). What I now want to argue is that this move is wellmotivated by other context-sensitive language.

For a first example, consider Angelika Kratzer's classic "restrictor" analysis of conditionals and their interaction with modals, ${ }^{32}$ an analysis that shares important features in common with QDR. Consider a sentence like

If there are at least three apples, then there must be at least two apples.

On the Kratzerian analysis, we account for (19)'s truth by seeing the antecedent of the conditional as restricting the domain over which the modal in the consequent quantifies. Given the restriction to the worlds in which there are at least three apples, it is true that in every remaining world, there are at least two apples. So (19) comes out true. The restriction is important because if we read 'must' as unrestricted, (19) appears to be false. For it can certainly be the case that there are at least three apples (contingently, at the actual world), but that it is not a necessary truth that there are at least two apples (at all possible worlds, with no restriction on which worlds are to count). But now suppose that we reformulate (19) as

(20) There must be at least two apples, if there are at least three apples.

To the best of my knowledge, no one sees this rewriting as posing a problem for the Kratzerian semantics. Even though 'if there are at least two apples' is syntactically posterior to 'there must be at least two apples' here, the latter is still capable of restricting the worlds over which the 'must' occurring in the former quantifies. The semantics just is not held hostage to the syntax here. What I am proposing about reversed concessive knowledge attributions is exactly analogous.

For a second example, note that contextualists often hold that certain claims are capable of changing the context so as to make themselves true, through so-called "accommodation." 33 For example, the pedantic utterance "it's not true that there's nothing in the fridge!" itself widens the domain over which the 'nothing' quantifies, perhaps to include almost-empty, moldy jars of mayonnaise. In this case, clearly, the relevant context for the use of 'nothing' is not the pre-utterance context, or even the context that results from the updates that have already been achieved at the precise second that the word 'nothing' is uttered. Rather, it is the context that results from the utterance of the full sentence. So, similarly, when one asserts the conjunction 'it is possible that not$p$, but I know that $p$ ', it is not that 'it is possible that not- $p$ ' gets to be true merely because the preutterance modal base did not include the proposition that one knows that $p$. What matters is the postutterance modal base - and in a case like this, where the distinctive badness is in the conjunction of two claims, we can plausibly claim that this is the modal base following the utterance of the whole conjunction.

For a final example, go back to the table example and to the gradable adjective 'flat'. When I say, "The table has little kinks and flecks on the surface, and is flat," this sounds bad. And in this

\footnotetext{
32 Kratzer, "The Notional Category of Modality," op. cit.

33 See, especially, David Lewis, "Scorekeeping in a Language Game," Journal of Philosophical Logic, VIII, 1 (1979): 339-59.
} 
case, it is overwhelmingly plausible that the badness results from the first conjunct driving up the standards for 'flat'. Yet it is equally bad to say, "The table is flat, and has little kinks and flecks on the surface." Again, this seems to be an example where the contextually relevant standards for 'flat' can depend on the second conjunct, even though the latter is syntactically posterior to the former. This, then, is a phenomenon that is quite general to context-sensitive language. So I do not think it is ad hoc to say that in reversed concessive knowledge attributions, the second conjunct can update the context that determines the semantic value of the first.

The explanation being given of reversed concessive knowledge attributions, then, turns out to be the same as the explanation given in the original cases. This is in contrast to the way in which the defender of KPL had to call on other principles to explain the cases that KPL had trouble with in section IV. In particular, it does not result in an account that explains the badness of some sentences semantically, and that of other (apparently very similar) sentences pragmatically.

\section{What about epistemic possibility?}

Here is a spurious argument for the KPL view. The KPL view is a claim about epistemic possibility. But 'epistemic' means 'to do with knowledge'. So 'epistemically possible' means 'possible as far as I know'. Just as the logically possible worlds are the ones compatible with the laws of logic and the metaphysically possible worlds are the ones compatible with necessary metaphysical truths, the epistemically possible worlds are the ones compatible with what you know. And from that it just follows that if you know that $p$, then it is not epistemically possible for you that not- $p$.

The reason that this argument is spurious is because it assumes that there is a single category of epistemic possibility, where 'epistemic' is construed narrowly to mean 'concerned with knowledge'. But this is something that the KPL advocate cannot just help herself to. We are giving a theory of speakers' uses of 'possible', not of 'epistemically possible'. The term 'epistemically possible' is a philosopher's term of art, a category used by philosophers to classify one use of 'possible'. ${ }^{34}$ But it is to prejudge the issue to assume that all the uses of 'possible' that we are trying to account for are best cashed out in terms of compatibility with a subject's knowledge. Call them 'epistemic' if you like, but not if this just stipulates that the subject's knowledge has to constitute the modal base for such claims.

On the present view, by contrast, the modal base is sensitive to what is said in a conversational context, and thus will not always be co-extensive with the speakers' knowledge, or even their common knowledge. In certain conversational contexts, where we treat things that we actually know as open questions, the modal base will be much narrower than that. And there can also, perhaps, be contexts where it includes things that we do not in fact know. There is nothing privileged about the set of propositions that the speaker knows that always makes it the relevant

\footnotetext{
34 And there are other possible terms we could have used. A relatively early work on modals_Alan R. White, Modal Thinking (Ithaca: Cornell University Press, 1975)_uses the term 'problematic possibility' to refer to what most philosophers call 'epistemic possibility'.
} 
modal base for the conversation, although naturally we will expect that the modal base and the speaker's knowledge will often be similar. ${ }^{35}$

Consider a favorite example of contextualism-inclined epistemologists. You are teaching a class on skepticism. You are trying to set up the basic problem by appealing to your favorite skeptical scenario. In introducing it, you say, "We could be brains in vats." What does the modal force of 'could' amount to here? On a standard picture, that underlying KPL, there is logical possibility, metaphysical possibility, epistemic possibility, and perhaps a few others. Is your claim one of epistemic possibility, where this means 'possible compatibly with our knowledge'? Certainly not-at least, not if you are a good teacher! For this amounts to the assertion that we do not know we are not brains in vats. But that is the question, or at least a large part of the question, that you want your students to discuss-you do not mean to set things up so that its answer is determined in advance! You are just setting up the skeptical problem by pointing out that we could be brains in vats-not giving the skeptical answer.

Is your claim, then, one of mere logical or metaphysical possibility? This does have the advantage, at least, of making your claim true (pace Putnam). But it does not seem like you are merely registering the logical or metaphysical possibility that we are brains in vats: there is a reason you picked this skeptical scenario. After all, consider the following scenario: you do not have hands - they were lost in an accident some years ago. Moreover, it does not visually appear to you as if you have hands. Nevertheless, you believe that you have hands. Call this the accident skeptical scenario. The accident skeptical scenario is both logically and metaphysically possible. But when you say "We could be brains in vats," this is meant to be felt as being possible in some way that the scenario I have just suggested is not. What way could that be?

Appealing to updates on the modal base helps us to resolve this puzzle. We are in the context of a conversation about whether we know we have hands. For the purposes of such a conversation, it is not in the modal base that we are not victims of some skeptical scenario like being brains in vats, though this proposition is in the modal base in almost every other context. So the modal base is relatively thin. This allows you to truly say, "We could be brains in vats." But we have not gone so far as to get rid of everything other than necessary metaphysical truths. So there will still be certain conditional propositions in the modal base, for example: if you had lost your hands in an accident, and it no longer appeared to you that you had hands, then you would not believe that you have hands'. This means, that in the relevant sense, the accident skeptical scenario is not a possibility.

The modal base is not only restricted for purposes of inquiry: there are contexts in which a speaker deliberately excludes his or her own knowledge from the modal base to avoid revealing its content to a conversational partner. Here are some examples:

(21) [Uttered with your hands behind your back]: The jack of hearts might be in my left hand_or it might be in my right hand—and only I know which! $!^{36}$

\footnotetext{
${ }^{35}$ For another account that recognizes this flexibility, see Anderson ("Fallibilism and the Flexibility of Epistemic Modals," op. cit.). Our accounts differ, however, with the important upshot that Anderson's does not explain why the utterance of "I know that $p$ " makes "it is possible that not- $p$ " false-indeed, she thinks that concessive knowledge attributions are sometimes okay.
} 
The KPL view cannot make sense of this at all. If you know which hand the card is in, or whether the cogito is on the test, then according to the KPL view, then at least one of your modal claims here is false. ${ }^{37}$ But the QDR view predicts this smoothly. Whichever proposition is true- $p$ or not- $p$ - it is not common ground between you and your interlocutor, despite your knowledge. So it is reasonable to think that it is not in the modal base either, in which case both possibility-claims come out true. The QDR view, to my knowledge uniquely, can allow this while still making sense of the badness of traditional 'I know that $p$, but it is possible that not- $p$ ' claims. It can do this precisely because its explanation of this badness is not in terms of the effect of knowing that $p$ on the truth-values of possibility-claims, but rather the effect of saying that you know that $p$ on these truth-values. (21) and (22) are cases where you know, but explicitly refuse to say what it is that you know. They thus provide another good set of test cases for comparing KPL and QDR, with the latter again coming out on top.

We should, then, throw off the straitjacket of assuming that any possibility-claim that is not one of logical or metaphysical possibility is a claim of epistemic possibility in the narrow sense of 'epistemic' meaning 'compatible with one's knowledge'. Rather, claims of possibility are always relative to a particular modal base, and we can think of logical possibility as the limiting case where this modal base contains nothing at all. Metaphysical possibility operates with an only slightly richer modal base: the metaphysically necessary truths. And then, rather than there being one single category of epistemic possibility, there can be possibility claims made against a background of modal bases with varying degrees of richness, depending on the context. ${ }^{38}$ For some purposes, like that of the lesson on skepticism, the modal base will be very thin indeed-perhaps such that it is closer to a bare metaphysical possibility claim than to an ordinary epistemic possibility claim, ${ }^{39}$ but nevertheless, as we have just seen, not so thin as to just be metaphysical possibility.

\section{Conclusion}

Reading the literature on epistemic modals, one would be forgiven for thinking that KPL_or some subtly adjusted variant - is the only game in town. It is not. One can reject KPL while maintaining that concessive knowledge attributions are false as false can be by embracing the QDR account. But it is not just that there is an alternative explanation out there. 'I think I know...' utterances provide

\footnotetext{
${ }^{36}$ I owe this example to Josh Knobe. Similar examples are also raised by Hawthorne, Knowledge and Lotteries, op. cit., p. 27; and von Fintel and Gillies, "An Opinionated Guide to Epistemic Modality," op. cit., p. 45.

${ }^{37}$ The same applies to KPL views that make reference to group knowledge, because such views (for example, DeRose, "Epistemic Possibilities," op. cit., p. 593) count group knowledge as anything that even one member of a group knows, not as the common knowledge of the group. A view that required common knowledge would give up on the claim that a subject cannot know something that is, for them, possibly false.

38 This makes the (many) epistemic reading(s) far more continuous with the logical and metaphysical senses of 'possible' than the received view. This is in the spirit of Kratzer's original proposals-indeed, she explicitly suggests that information weaker than knowledge can sometime get into the modal base. See Kratzer, "Modality," in A. von Stechow and D. Wunderlich, eds., Semantik: Ein internationales Handbuch zeitgenössischer Forschung (Berlin: de Gruyter, 1991 ): 645. 39 Or even thinner-where the metaphysical facts are in doubt.
} 
positive grounds to reject KPL_or anything like it-and to accept QDR, and the claim that subjects can have knowledge of propositions that are, for them, possibly false.

More broadly, I believe that the idea behind KPL-that there is a distinctive category of modality called 'epistemic modality', where this is concerned narrowly with the knowledge of subjects or even groups, is a philosophical dogma. In rejecting it and liberalizing our account of modal terms, we are freed to better explain the way that speakers actually use 'possible'.

ALEX WORSNIP

New York University 